\title{
Activation of EGFR-PI3K-AKT signaling is required for Mycoplasma hyorhinis-promoted gastric cancer cell migration
}

\author{
Hongying Duan, Like Qu and Chengchao Shou*
}

\begin{abstract}
Persistent infection of Mycoplasma hyorhinis (M. hyorhinis) was associated with gastric cancer cell migration and invasion, but the mechanisms were not well understood. Herein, we found that M. hyorhinis activated phosphoinositide 3-kinase (PI3K)-AKT signaling axis in gastric cancer cell lines. Epidermal growth factor receptor (EGFR) was upstream of PI3K-AKT signaling in the context of $M$. hyorhinis infection, because phosphorylation of AKT Serine 473 was almost completely attenuated by the EGFR inhibitor AG1478 or by EGFR knockdown. Phosphorylation of AKT S473 induced by M. hyorhinis infection was also abolished by PI3K inhibitor wortmannin. Furthermore, we found that P37, a membrane protein of $M$. hyorhinis, could also promote M. hyorhinis-induced PI3K-AKT signaling activation and cell migration. In addition, pre-treatment with AG1478 or wortmannin significantly inhibited cell migration induced by M. hyorhinis infection or p37 treatment. In conclusion, EGFR-PI3K-AKT signaling plays an important role in M. hyorhinis-promoted cell migration in gastric cancer cells, thus providing a clue to the pathogenesis of M. hyorhinis in gastric cancer.
\end{abstract}

Keywords: Mycoplasma hyorhinis, Gastric cancer, p37, PI3K-AKT, EGFR

\section{Introduction}

Infectious agents, such as viruses, bacteria, and parasites, have been identified as risk factors for certain typess of cancer [1]. The most famous are the association of Helicobacter pylori with gastric cancer and that of human papillomavirus with cervical cancer [2,3]. Identifying the roles of infectious agents in carcinogenesis and cancer development will provide more efficacious methods for prevention and therapies of these malignancies.

Mycoplasma hyorhinis (M. hyorhinis) belongs to mycoplasmas (Class Mollicutes), which are small-sized, wallfree prokaryotic organisms. The first study reporting the association of mycoplasma with cancer was in the mid1960s. This study revealed the association between mycoplasma infection and leukemia [4]. To date, there have been several lines of clinical evidence linking mycoplasma infection to different types of cancer [5-7]. As reported by Barykova et al., M. hominis was present at three time

\footnotetext{
* Correspondence: shouchengchao@gmail.com

Department of Biochemistry and Molecular Biology, Peking University Cancer Hospital \& Institute, Key Laboratory of Carcinogenesis and Translational Research (Ministry of Education), 52 Fucheng Road, Beijing 100142, China
}

higher frequency in patients with prostate cancer than in those with benign prostatic hyperplasia [7]. Meanwhile, several studies including ours have reported a potential link between M. hyorhinis infection and cancer [8-11]. We previously examined $M$. hyorhinis infection in over 600 human tissues using a monoclonal antibody PD4 against $M$. hyorhinis lipoprotein $\mathrm{p} 37$, and found that $56 \%$ of gastric carcinoma and $55 \%$ of colon carcinoma cases were $M$. hyorhinis-positive, suggesting an association between $M$. hyorhinis infection and cancer [8]. Moreover, we showed that $M$. hyorhinis infection in gastric cancer tissues positively correlates with tumor metastasis [10]. The phenotypic assays revealed that $M$. hyorhinis could promote cancer cell migration and invasion in vitro and metastasis in vivo [10]. Taken together, these results support a strong link between $M$. hyorhinis infection and cancer metastasis.

p37, a lipoprotein of M. hyorhinis, has no homology to any human proteins [12]. Our studies revealed that p37 enhanced the invasiveness and metastasis of gastric cancer cells in vitro and in vivo [13]. Another study reported that recombinant p37 induced anaplasia and 
promoted migration in prostate cancer cells [9]. However, mechanisms underlying $M$. hyorhinis' and p37's pro-invasive capacities are unclear.

Cancer metastasis is a multi-step process that includes: 1) vascularization of the primary tumor; 2) detachment and invasion of cancer cells; 3 ) intravasation into lymphatic and blood vessels; 4) survival and arrest in the circulation; 5) extravasation into distant organs; and 6) colonization and growth of metastatic tumors [14]. Nearly $90 \%$ cancer-related mortality is caused by cancer metastasis [15]. The signaling pathways involved in cancer metastasis are investigated in great detail in the past decades [16]. Among these pathways, deregulation of phosphoinositide 3-kinase (PI3K)-AKT signaling axis was observed in various kinds of cancer [17]. Previous studies uncovered the central role of PI3K-AKT signaling in several cellular processes involved in cancer, including metabolism, growth, survival, and motility [17-20].

To clarify whether PI3K-AKT signaling is activated in $M$. hyorhinis-infected gastric cancer cells and its role in cell migration, we designed and performed this study. We unveiled that $M$. hyorhinis activates PI3K-AKT signaling in gastric cancer cells in an epidermal growth factor receptor (EGFR)-dependent fashion. The activated EGFR-PI3K-AKT pathway plays an important role in M. hyorhinis-induced cancer cell migration.

\section{Results}

M. hyorhinis binds to gastric cancer cell MGC803 in a time and dose-dependent manner

Our previous work has shown that $M$. hyorhinis could infect human gastric cancer cells $[8,10]$. Herein, through immunofluorescence staining with DAPI, we observed that $M$. hyorhinis could attach to cell membrane. $M$. hyorhinis bound to gastric cancer cell MGC803 in a time and dose-dependent manner. When $1 \times 10^{5} \mathrm{CCU} / \mathrm{mL}$ $M$. hyorhinis was added in the cell culture medium and incubated with cells for 24 hours, peri-nuclear DNA staining was clearly seen by confocal microscopy immunofluorescence assay (Figure 1A). p37 protein is the most abundant membrane moiety of $M$. hyorhinis [12]. In this study, we found that recombinant GST-p37 fusion protein, but not GST, could adhere to MGC803 cell membrane, as shown by immunofluorescence staining with PD4 antibody (Figure 1B), suggesting that p37 may exert some roles in $M$. hyorhinis infection of human cells.

Both $M$. hyorhinis and GST-p37 activate PI3K-AKT signaling We previous reported that $M$. hyorhinis could induce cancer cell migration and invasion [10]. Our study also revealed that both purified p37 protein and adenovirusmediated overexpression of p37 could promote AGS gastric cancer cell invasiveness and metastasis [13]. PI3K-AKT signaling is deregulated in a range of human cancers and is thought to promote tumorigenesis and cancer metastasis [21]. We noticed that phosphorylations of PI3K and AKT were increased in M. hyorhinis-infected MGC803 and BGC823 cells, while total levels of these two proteins were stable (Figure 2A). When the cells were treated with GSTp37 in different doses for 2 hours, the PI3K and AKT were also dramatically activated (Figure 2B), suggesting that p37 alone is sufficient to induce PI3K and AKT phosphorylations upon M. hyorhinis infection.

\section{PI3K-AKT signaling is downstream of EGFR in $M$. hyorhinis-infected MGC803 cells}

We found that $M$. hyorhinis-induced phosphorylation of AKT S473 was attenuated by PI3K inhibitor wortmannin (Figure 3A), confirming that PI3K is upstream of AKT in the context of $M$. hyorhinis infection. PI3K-AKT signaling can be activated by multiple stimuli. Growth factor receptor family proteins belong to major upstream molecules of PI3K-AKT signaling [22]. EGFR was shown to be involved in Helicobacter pylori-induced activation of EGFR-PI3K signaling in AGS cells [23,24]. Interestingly, phosphorylation of EGFR Y1068 was increased in M. hyorhinis infected cells (Figure 2A). To explore the role of EGFR in M. hyorhinis-promoted PI3K-AKT signaling, we utilized EGFR kinase inhibitor AG1478 and RNA interference strategies respectively. After AG1478 pre-treatment, we found that phosphorylation of AKT S473 in M. hyorhinis-infected MGC803 cells was reversed to the level similar to that in non-infected counterpart (Figure 3A). Alternatively, when EGFR expression was knocked down by a specific siRNA (Figure 3B), M. hyorhinis infection-induced phosphorylation of AKT S473 was also counteracted (Figure 3C).

\section{PI3K-AKT signaling is required for $M$. hyorhinis infection and induced cell migration in MGC803 cells}

Next, we sought to determine the contribution of PI3KAKT signaling to $M$. hyorhinis infection. We found that the infection of MGC803 cells were partially blocked by AG1478 and wortmannin, as shown by lowered band intensity of $p 37$ in PCR assay (Figure 4A). Meanwhile, we found these two inhibitors significantly lowered $M$. hyorhinis- and p37-induced cell migration (Figure 4B and C), suggesting that activated EGFR-PI3K-AKT axis is responsible for M. hyorhinis- or p37-induced cell invasiveness.

\section{Discussion}

Epidemiologic and molecular studies suggest that microbial infections are associated with certain cancers. It has been suggested that there is an association between mycoplasma infection and different cancers $[25,26]$. Since the anti-tumor monoclonal antibody PD4 was developed by our lab [27], we sought to identify the antigen of PD4. 

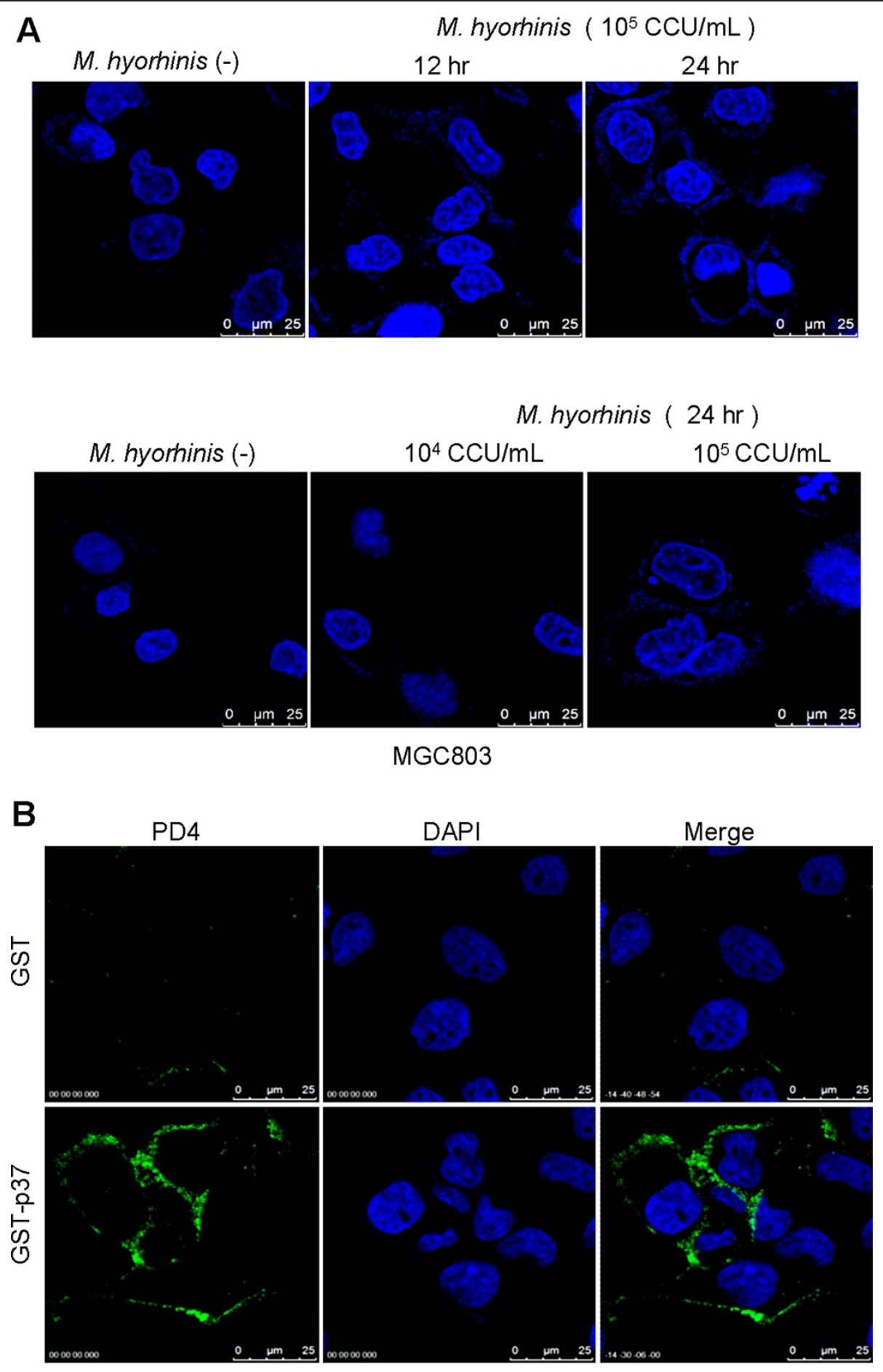

MGC803

Figure 1 M. hyorhinis binds to gastric cancer cell MGC803 in a time and dose-dependent manner. (A) M. hyorhinis binds to MGC803 cells in a time- and dose-dependent manner. The cells were exposed to $10^{4}, 10^{5} \mathrm{CCU}$ (color changing units)/ $\mathrm{mL}$ of $\mathrm{M}$. hyorhinis for 24 hours, or $10^{5}$ $\mathrm{CCU} / \mathrm{mL}$ of $M$. hyorhinis for 0 (unexposed), 12 and 24 hours. DAPI staining was performed at indicated time points. Titer of M. hyorhinis was quantified as color-change-units (CCU) per milliliter. One CCU equals to one organism of mycoplasma. Unless specified, we used $10^{5} \mathrm{CCU} / \mathrm{mL}$ M. hyorhinis to infect cells. By normalizing to the amount of cells to be infected, the multiplicity of infection (MOI) was 0.1 for $10^{4} \mathrm{CCU} / \mathrm{mL}$ and 1 for $10^{5} \mathrm{CCU} / \mathrm{mL}$. (B) p37 binds to MGC803 cells. The cells were treated with 300 pmol GST-p37 for 24 hours. Immunofluorescence assay with PD4 antibody was performed after 24 hours. GST was used as negative control. 

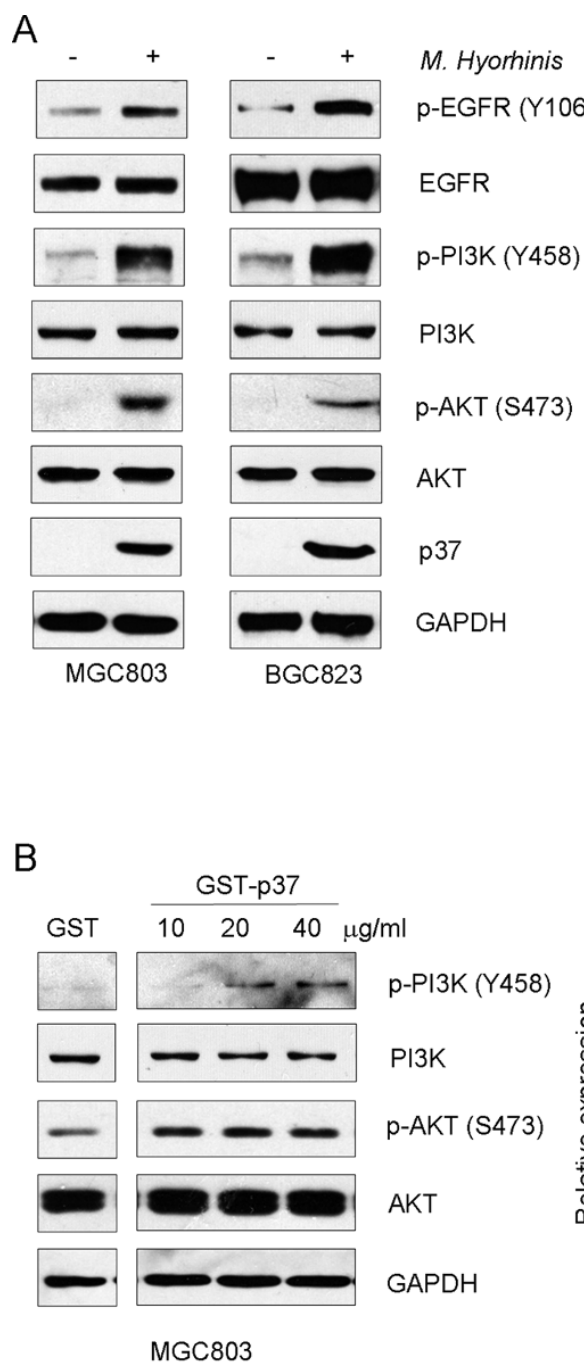
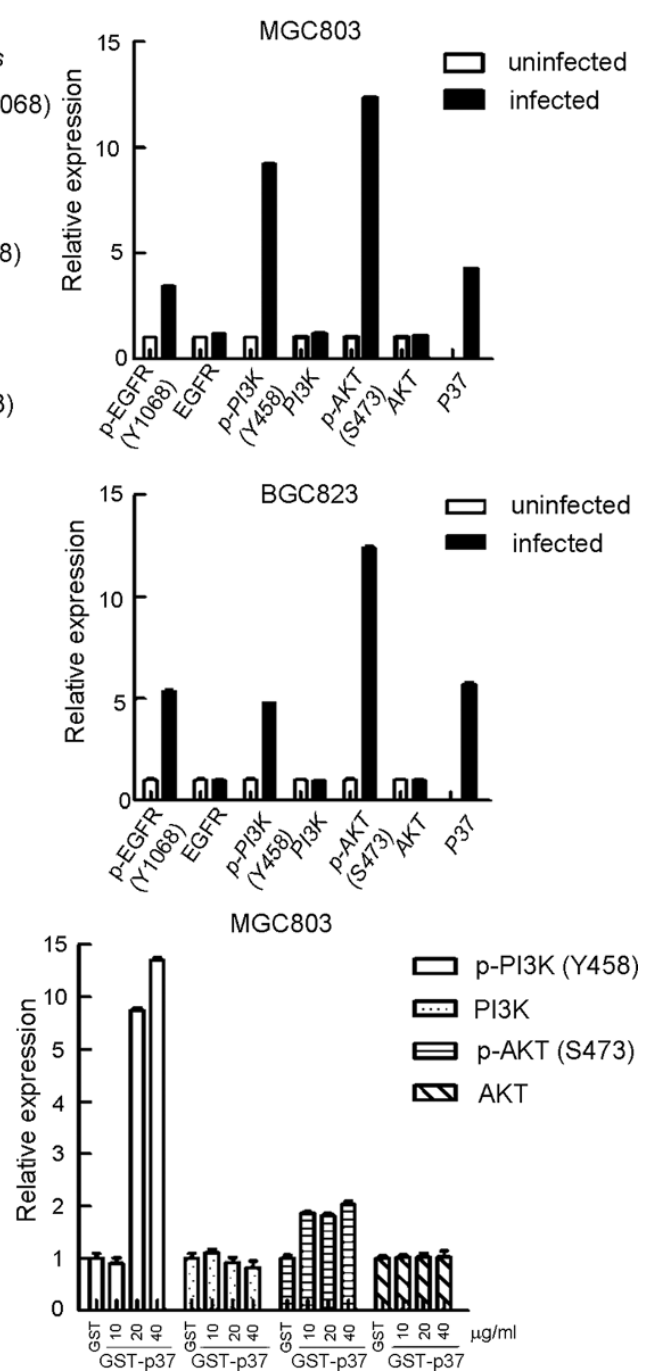

Figure 2 Both $M$. hyorhinis and p37 activate PI3K-AKT signaling. (A) M. hyorhinis upregulates EGFR, PI3K and AKT phosphorylations in gastric cancer cell MGC803 and BGC823. Cells were serum starved for 24 hours and then infected with M. hyorhinis for another 2 hours. Protein lysates were analyzed by Western blot with indicated antibodies. (B) Purified p37 protein upregulates PI3K and AKT phosphorylations in gastric cancer cell MGC803. Cells were serum starved for 24 hours and then treated with p37 for another 2 hours. Protein lysates were analyzed by Western blot with indicated antibodies. Optical densities of protein bands were quantified by Image J software and relative expression levels of indicated protein to loading control were shown in graph. Values represented the mean \pm SD from three to four independent experiments.

Surprisingly, the antigen recognized by PD4 was characterized as a lipoprotein from $M$. hyorhinis, namely p37 [28]. Immunohistochemical studies utilizing PD4 suggested a strong association of $M$. hyorhinis infection with cancer metastasis $[8,10]$.

Most cancer-related deaths are caused by metastasis [15]. Several signaling pathways were shown to be responsible for this process [16]. Among them, PI3K-AKT signaling was investigated in great detail [17-20]. In the present study, phosphorylations of PI3K and AKT were found to be upregulated after $M$. hyorhinis infection or by treatment with recombinant p37 protein. These results suggested that PI3K-AKT signaling was activated in the process of $M$. hyorhinis infection, which might be mediated by its membrane protein p37. PI3K, consisting of a regulatory subunit $\mathrm{p} 85$ and a catalytic subunit p110, is often activated by growth factor stimulation through receptor tyrosine kinases (RTKs) [29-31]. The regulatory subunit, p85, directly binds to phosphotyrosine residues on RTKs. This binding relieves the intermolecular inhibition of the p110 catalytic subunit by $\mathrm{p} 85$ and localizes PI3K to the plasma membrane where its substrate, phosphatidylinositol 4, 5-bisphosphate, resides [30]. These RTKs are often mutated, amplified, or overexpressed in cancers, causing aberrant PI3K activation [30]. For example, PI3K is activated by EGFR in lung cancers harboring somatic activating mutations in EGFR, and by human epidermal growth factor receptor 


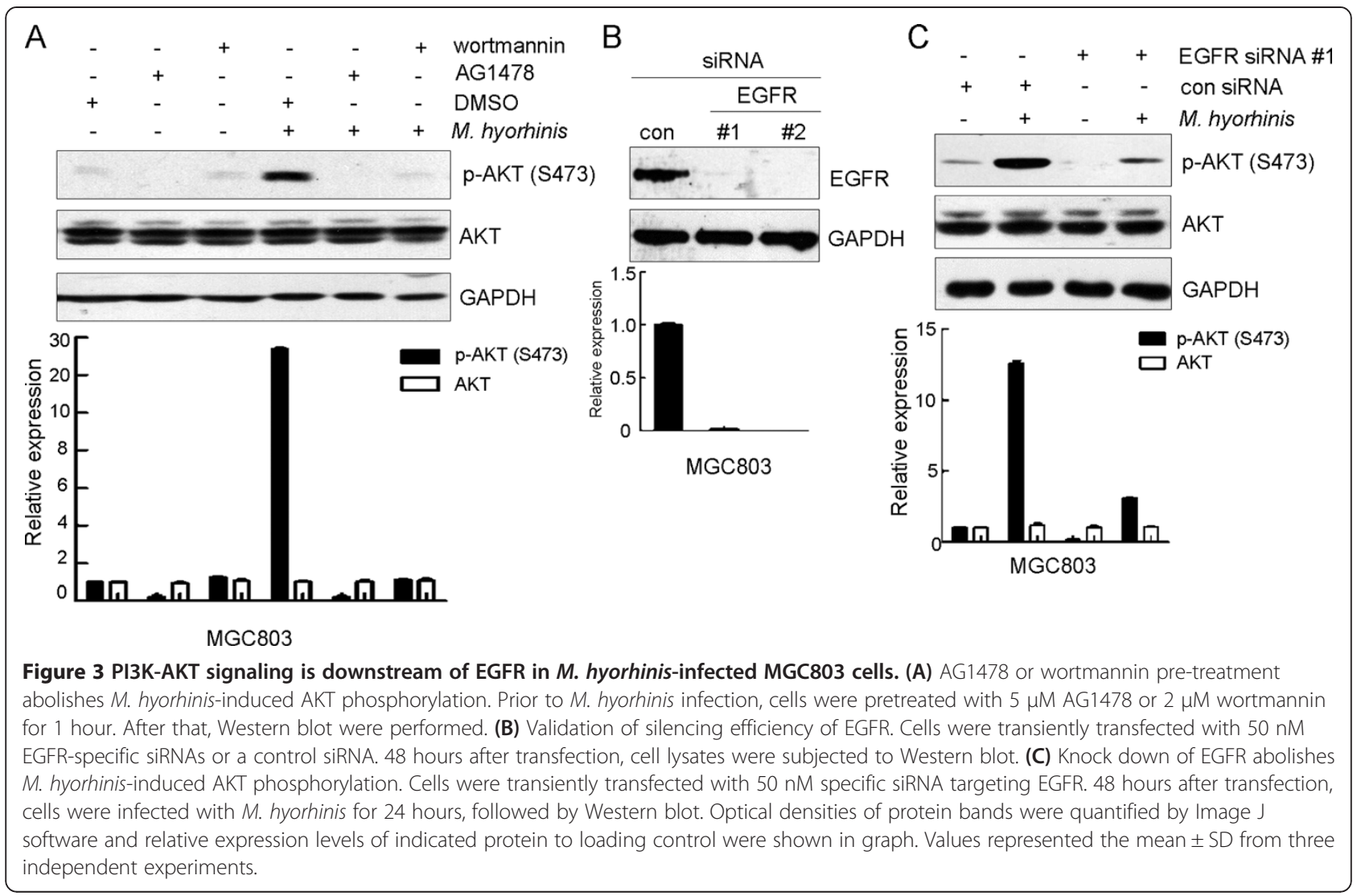

2 (HER2) in breast cancers with HER2 amplification $[29,32,33]$. In the context of $M$. hyorhinis infection, EGFR was phosphorylated and activated [10]. In this study, to assess the role of EGFR in M. hyorhinis-induced PI3KAKT signaling activation, both chemical inhibition of EGFR by AG1478 and knockdown of EGFR via RNAi were applied. We found that $M$. hyorhinis infection-induced phosphorylations of PI3K and AKT were dependent on EGFR, therefore $M$. hyorhinis infection could induce activation of EGFR-PI3K-AKT signaling. As to how $M$. hyorhinis infection activates EGFR, we propose that $M$. hyorhinis may bind to certain cell surface protein(s) via p37, in turn recruiting EGFR on the cell membrane and promoting EGFR homodimerization or heterodimerization with other epidermal growth factor family proteins. After dimerization, EGFR was autophosphorylated and then phosphorylated downstream signaling targets such as PI3K. In the future work, we will focus on the work searching for cellular factors mediating $M$. hyorhinis infection-induced downstream signaling events.

Activated PI3K catalyzes the synthesis of the membrane phospholipid phosphatidylinositol 3,4,5-triphosphate from phosphatidylinositol 4,5-bisphosphate, thus recruiting AKT to the plasma membrane by direct interaction of phosphatidylinositol 3,4,5-triphosphate with the AKT pleckstrin homology (PH) domain [34]. Several studies have reported increased AKT phosphorylation and protein expression in tumors of the breast, prostate, ovary, and pancreas [35-38]. Once phosphorylated, AKT relocalizes to subcellular compartments where it phosphorylates substrates to exert distinct functions, such as cell growth, survival, anti-apoptosis and cell migration $[20,39,40]$. Among the above-mentioned cellular processes, the major function of AKT is its role in promoting cell growth [39]. The contribution of this signaling axis to cell proliferation and survival has already been widely discussed. The classical mechanism appears to be through activation of the mammalian target of rapamycin complex 1 (mTORC1), which is regulated by both nutrients and growth factor signaling [41]. However, growth and survival are not the only phenotypes that exist in carcinomas. Additionally, cell migration and invasion are also important phenotypes that are responsible for the progression of primary tumors into metastases [20]. Pro-migratory function of PI3K-AKT signaling has been underscored by some recent studies $[20,42,43]$. A key discovery made by the Mercurio laboratory, showed that the alpha6beta4 integrin, a tumor-associated antigen, promoted breast and colon cancer cell migration and invasion by activating PI3K-AKT signaling [44]. Furthermore, AKT can stimulate secretion of matrix metalloproteases that are required for degradation of the extracellular matrix [45]. In fibroblasts, AKT signaling enhances activation of various small GTPases, including 


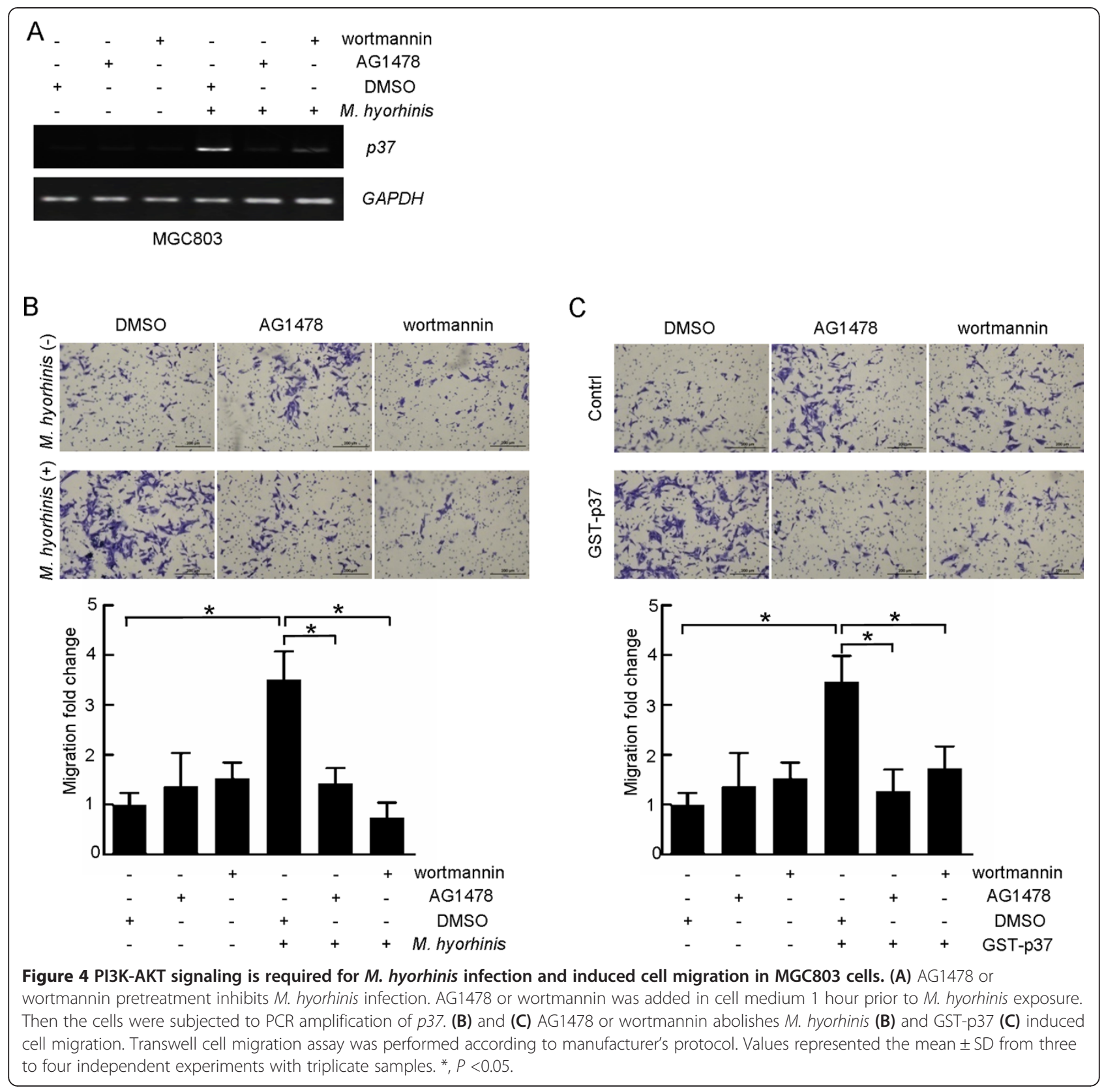

Rac, and thus leading to remodeling of the actin cytoskeleton and enhanced cell motility [46]. Similarly, expression of activated AKT in fibrosarcoma or pancreatic cancer cells increases their invasion through Matrigel, an effect recapitulated by overexpression of AKT in breast and ovarian cancer cells $[45,47,48]$. Expression of AKT can also promote epithelial-mesenchymal transition (EMT), a process intimately associated with tumor progression to invasive and metastatic carcinoma [49]. In the present study, we found that AKT is activated in M. hyorhinis-infected gastric cancer cells, and this activation is required for M. hyorhinisand p37-induced cell migration in gastric cancer cells. Our results support the point that PI3K-AKT axis plays an important role in M. hyorhinis infection and M. hyorhinisinduced cancer cell migration. Because AKT phosphorylates different targets involved in a large variety of cellular processes, it is possible that $M$. hyorhinis-induced AKT activation might affect other aspects of cellular processes, such as anti-apoptosis, a possibility need to be validated in the future work.

Not surprisingly, the PI3K-AKT pathway has attracted great attention in attempts to develop specific inhibitors as therapy for various cancers, and numerous agents were developed [50,51]. In this study, we discovered activation of the EGFR-PI3K-AKT pathway after M. hyorhinis infection in gastric cancer cells, which may provide valuable 
evidence for patient-directed therapies of $M$. hyorhinispositive gastric cancer patients.

\section{Materials and methods Cell culture}

MGC803 gastric cancer cell line was from a 53-year-old male Chinese with poorly differentiated mucoid adenocarcinoma, while BGC823 gastric cancer cell line was from a 62-year-old male Chinese with poorly differentiated adenocarcinoma. Both cell lines were cultured in RPMI-1640 medium supplemented with $10 \%$ fetal bovine serum $(\mathrm{FBS})$ and incubated in $5 \% \mathrm{CO} 2$ at $37^{\circ} \mathrm{C}$. The culture media and FBS were obtained from Invitrogen (Carlsbad, CA, US). Mycoplasma test was routinely performed by PCR amplification of M. hyorhinis $p 37$ and DAPI staining of mycoplasma DNA.

\section{Mycoplasma propagation and co-culture}

M. hyorhinis was grown for $3-4$ days at $37^{\circ} \mathrm{C}$ in Hayflick's medium [52]. M. hyorhinis was serially passaged for 3 times and harvested by centrifugation for $20 \mathrm{~min}$ at $12,000 \mathrm{~g}$, washed once in PBS, resuspended in PBS, and stored at $-80^{\circ} \mathrm{C}$. Titer of $M$. hyorhinis was quantified as color change units (CCU) per milliliter as described previously [53]. MGC803 and BGC823 cells were serumstarved for 24 hours prior to addition of M. hyorhinis. Cells were incubated with $M$. hyorhinis for 24 hours before experiment.

\section{Reagents and antibodies}

GST and GST-p37 fusion proteins were expressed and purified by our lab. AG1478 was purchased from Sigma-Aldrich (St Louis, MO, US) and wortmannin was purchased from Cell Signaling (Danvers, MA, US). Both of them were dissolved in DMSO, aliquoted and stored at $-20^{\circ} \mathrm{C}$. Anti-phospho-EGFR (Y1068) (\#2234), antiphospho-PI3K (S458) (\#4228), anti-phospho-AKT (S473) (\#4060), anti-PI3K (\#4257), and anti-AKT (\#4691) antibodies were purchased from Cell Signaling. Anti-AKT antibody (BS1784) was purchased from Bioworld (St. Louis Park, MN, US). Anti-p37 monoclonal antibody PD4 was generated in our lab [27].

\section{Immunofluorescence}

Cells were grown on the coverslips and fixed with $4 \%$ paraformaldehyde for $20 \mathrm{~min}$ at room temperature, followed by blocking with $5 \%$ bovine serum albumin at room temperature for 1 hour. The cells were incubated with PD4 overnight at $4^{\circ} \mathrm{C}$, followed by washing with PBS/ $0.1 \%$ Tween-20 and probing with FITC-conjugated antimouse antibody for $45 \mathrm{~min}$ at room temperature in dark. After washing with PBS/0.1\% Tween-20 for 3 times, the cells were counterstained with DAPI and mounted on $50 \%$ glycerol/PBS. For the staining of M. hyorhinis DNA, cells were directly stained with DAPI and mounted on 50\% glycerol/PBS after blocking. A Leica SP2 confocal microscope (Leica Microsystems, Dresden, Germany) was used to observe the localization of p37 or M. hyorhinis DNA.

\section{Small interference RNA (RNAi) transfection}

Cells were plated in 12-well plates and transfected with siRNA mate (GenePharma, Shanghai, China) according to the manufacturer's protocol. The target sequences were as follows: EGFR \#1 5'-CCACCUCUCUACCUUAAUATT-3', \#2 5'-GGGCUUAGAACAACUAGAATT-3'. Negative control siRNA sequence was 5'-ACACGAGAUAAUAUCGAC UUG-3'. siRNAs were synthesized by GenePharma (Shanghai, China).

\section{Western blot}

Cells were washed twice with cold PBS and then lysed in lysis buffer $(25 \mathrm{mM}$ Tris- $\mathrm{HCl} \mathrm{pH} 7.4,150 \mathrm{mM} \mathrm{NaCl}$, $1 \mathrm{mM}$ EDTA, 1\% NP-40, 10\% glycerol, and $1 \times$ complete protease inhibitors). The proteins of the lysates were quantified with $\mathrm{BCA}^{\mathrm{TM}}$ Protein Assay Kit (Thermo Fisher, Waltham, MA, US). $50 \mu \mathrm{g}$ of total proteins were subjected to Western blot with indicated antibodies and GAPDH was used as loading control.

\section{DNA extraction and detection of $M$. hyorhinis by PCR}

DNA was isolated from cells by digestion with $50 \mathrm{mM}$ Tris $\mathrm{pH}$ 8.5, $1 \mathrm{mM}$ EDTA, $0.5 \%$ Tween-20, and $200 \mathrm{mg} / \mathrm{L}$ proteinase $\mathrm{K}$, followed by phenol/chloroform/isoamyl alcohol extraction and sodium acetate precipitation. DNA precipitates were washed with $70 \%$ ethanol, dried, and dissolved in $20 \mu \mathrm{L}$ sterile water. PCR was performed with $0.5 \mu \mathrm{g}$ extracted DNA and p37-specific primers (forward: 5'-GTAGTCAAGCAAG AGGATGT-3', reverse: 5'-GCTGGAGTTATTATACC AGGA-3') [54]. For PCR, the DNA was denatured at $94^{\circ} \mathrm{C}$ for 5 min first, followed by 30 cycles of $94^{\circ} \mathrm{C}$ for $30 \mathrm{sec}, 50^{\circ} \mathrm{C}$ for $30 \mathrm{sec}$, and $72^{\circ} \mathrm{C}$ for $60 \mathrm{sec}$, then at $72^{\circ} \mathrm{C}$ for $10 \mathrm{~min}$. The PCR products were analyzed by agarose gel electrophoresis. GAPDH was amplified as loading control.

\section{Cell migration assay}

Tissue culture-treated $6.5-\mathrm{mm}$ Transwell chamber with 8.0- $\mu \mathrm{m}$ pore membranes (Corning, Corning, NY, US) was used. Each well of 24-well plates was filled with $800 \mu \mathrm{L}$ medium containing $10 \%$ FBS. $3 \times 104$ cells, containing $M$. hyorhinis plus inhibitors or DMSO, were transferred onto the top chamber of each Transwell apparatus $(100 \mu \mathrm{L} /$ chamber). Cells were incubated for 24 hours at $37^{\circ} \mathrm{C}$. After that the chambers were then fixed in methanol, stained with hematoxylin, and counted in five randomly selected microscopic fields per well. Each sample was prepared in triplicate chambers and each experiment was repeated for at least 3 times. 


\section{Statistical analysis}

The data were analyzed by ANOVA. The statistical analysis was done using SPSS 11.0 software (SPSS) and $P<0.05$ was considered significantly.

\section{Ethical approval}

No experiment was carried out on humans or animals.

\section{Abbreviations}

CCU: Color changing units; EGFR: Epidermal growth factor receptor: EMT: Epithelial-mesenchymal transition; FBS: Fetal bovine serum; HER2: Human epidermal growth factor receptor 2; M. hyorhinis: Mycoplasma hyorhinis; mTORC1: mammalian target of rapamycin complex 1; PH: Pleckstrin homology; PI3K: Phosphoinositide 3-kinase; RTKs: Receptor tyrosine kinases.

\section{Competing interests}

The authors declare that they have no competing interests.

\section{Authors' contribution}

CS conceived project. CS, HD designed experiments. HD performed experiments. CS, HD, and LQ analyzed data. HD wrote the manuscript LQ provided writing assistance. All authors read and approved the final manuscript.

\section{Acknowledgments}

This work was supported by National Natural Science Foundation of China (No. 91029713) and National Basic Research Program of China (No. 2015CB553906).

Received: 23 June 2014 Accepted: 20 November 2014 Published online: 05 December 2014

\section{References}

1. Ferlay J, Shin HR, Bray F, Forman D, Mathers C, Parkin DM: Estimates of worldwide burden of cancer in 2008: GLOBOCAN 2008. Int J Cancer 2008, 2010(127):2893-2917.

2. Nomura A, Stemmermann GN, Chyou PH, Kato I, Perez-Perez GI, Blaser MJ: Helicobacter pylori infection and gastric carcinoma in a population of Japanese Americans in Hawaii. N Engl J Med 1991, 325:1132-1136.

3. Walboomers JM, Jacobs MV, Manos MM, Bosch FX, Kummer JA, Shah KV, Snijders PJ, Peto J, Meijer CJ, Muñoz N: Human papillomavirus is a necessary cause of invasive cervical cancer worldwide. J Pathol 1999, 189:12-19.

4. Paton GR, Jacobs JP, Perkins FT: Chromosome changes in human diploid-cell cultures infected with Mycoplasma. Nature 1965, 207:43-45.

5. Chan PJ, Seraj IM, Kalugdan TH, King A: Prevalence of mycoplasma conserved DNA in malignant ovarian cancer detected using sensitive PCR-ELISA. Gynecol Oncol 1996, 63:258-260.

6. Kidder M, Chan PJ, Seraj IM, Patton WC, King A: Assessment of archived paraffin-embedded cervical condyloma tissues for mycoplasma-conserved DNA using sensitive PCR-ELISA. Gynecol Oncol 1998, 71:254-257.

7. Barykova YA, Logunov DY, Shmarov MM, Vinarov AZ, Fiev DN, Vinarova NA, Rakovskaya IV, Baker PS, Shyshynova I, Stephenson AJ: Association of Mycoplasma hominis infection with prostate cancer. Oncotarget 2011, 2:289-297.

8. Huang S, Li JY, Wu J, Meng L, Shou CC: Mycoplasma infections and different human carcinomas. World J Gastroenterol 2001, 7:266-269.

9. Namiki K, Goodison S, Porvasnik S, Allan RW, Iczkowski KA, Urbanek C, Reyes L, Sakamoto N, Rosser CJ: Persistent exposure to mycoplasma induces malignant transformation of human prostate cells. PLOS One 2009, 4:e6872.

10. Yang H, Qu L, Ma H, Chen L, Liu W, Liu C, Meng L, Wu J, Shou C: Mycoplasma hyorhinis infection in gastric carcinoma and its effects on the malignant phenotypes of gastric cancer cells. BMC Gastroentero/ 2010, 10:132.

11. Urbanek C, Goodison S, Chang M, Porvasnik S, Sakamoto N, Li CZ, Boehlein SK, Rosser CJ: Detection of antibodies directed at M hyorhinis p37 in the serum of men with newly diagnosed prostate cancer. BMC Cancer 2011, 11:233.
12. Sippel KH, Robbins AH, Reutzel R, Boehlein SK, Namiki K, Goodison S, Agbandje-McKenna M, Rosser CJ, McKenna R: Structural insights into the extracytoplasmic thiamine-binding lipoprotein p37 of Mycoplasma hyorhinis. J Bacterio/ 2009, 191:2585-2592.

13. Gong $M$, Meng $L$, Jiang B, Zhang J, Yang H, Wu J, Shou C: p37 from Mycoplasma hyorhinis promotes cancer cell invasiveness and metastasis through activation of MMP-2 and followed by phosphorylation of EGFR. Mol Cancer Ther 2008, 7:530-537.

14. Le XF, Merchant O, Bast RC, Calin GA: The roles of MicroRNAs in the cancer invasion-metastasis cascade. Cancer Microenviron 2010, 3:137-147.

15. Weigelt $B$, Peterse $J L$, van't Veer LJ: Breast cancer metastasis: markers and models. Nat Rev Cancer 2005, 5:591-602.

16. Biancoa R, Melisia D, Ciardiellob F, Tortoraa G: Key cancer cell signal transduction pathways as therapeutic targets. Eur J Cancer 2006, 42:290-294.

17. Engelman JA, Luo J, Cantley LC: The evolution of phosphatidylinositol 3-kinases as regulators of growth and metabolism. Nat Rev Genet 2006, 7:606-619.

18. Dummler $B$, Hemmings BA: Physiological roles of PKB/Akt isoforms in development and disease. Biochem Soc Trans 2007, 35:231-235.

19. Fayard E, Xue G, Parcellier A, Bozulic L, Hemmings BA: Protein kinase B (PKB/Akt), a key mediator of the PI3K signaling pathway. Curr Top Microbiol Immunol 2010, 346:31-56.

20. Xue G, Hemmings BA: PKB/Akt-dependent regulation of cell motility. J Natl Cancer Inst 2013, 105:393-404.

21. Shukla S, MacLennan GT, Hartman DJ, Fu P, Resnick MI, Gupta S: Activation of PI3K-Akt signaling pathway promotes prostate cancer cell invasion. Int J Cancer 2007, 121:1424-1432.

22. O'Reilly KE, Rojo F, She QB, Solit D, Mills GB, Smith D, Lane H, Hofmann F, Hicklin DJ, Ludwig DL: mTOR Inhibition induces upstream receptor tyrosine kinase signaling and activates Akt. Cancer Res 2006, 66:1500-1508

23. Keates S, Keates AC, Katchar K, Peek RM Jr, Kelly CP: Helicobacter pylori induces up-regulation of the epidermal growth factor receptor in AGS gastric epithelial cells. J Infect Dis 2007, 196:95-103.

24. Tabassam FH, Graham DY, Yamaoka Y: Helicobacter pylori activate epidermal growth factor receptor- and phosphatidylinositol 3-OH kinase-dependent Akt and glycogen synthase kinase $3 \beta$ phosphorylation. Cell Microbiol 2009, 11:70-82.

25. Pehlivan M, Itirli G, Onay H, Bulut H, Koyuncuoglu M, Pehlivan S: Does Mycoplasma sp. play role in small cell lung cancer? Lung Cancer 2004, 45:129-130.

26. Hrbacek J, Urban M, Hamsikova E, Tachezy R, Eis V, Brabec M, Heracek J: Serum antibodies against genitourinary infectious agents in prostate cancer and benign prostate hyperplasia patients: a case-control study. BMC Cancer 2011, 11:53.

27. Dong ZW, Wan WH, Li ZP, Qiu WR, Wei SM: A monoclonal antibodies PD4 against gastric cancer cell line MGC803. Shengwu Huaxue Zazhi 1985, 1:52-58.

28. Ning JY, Sun GX, Huang S, Ma H, An P, Meng L, Song SM, Wu J, Shou CC: Identification of antigens by monoclonal antibody PD4 and its expression in Escherichia coli. World J Gastroenterol 2003, 9:2164-2168.

29. Engelman JA, Zejnullahu K, Mitsudomi T, Hyland C, Oh Park J, Lindeman N, Gale CM, Zhao X, Christensen J, Rogers RM: Mechanisms of activating PI3K signaling in lung cancers that become resistant EGFR tyrosine kinase inhibitors: D2-07. J Thorac Oncol 2007, 2:396.

30. Courtney KD, Corcoran RB, Engelman JA: The PI3K Pathway As Drug Target in Human Cancer. J Clin Oncol 2010, 28:1075-1083.

31. Chen YT, Tan KA, Pang LY, Argyle DJ: The class I PI3K/Akt pathway is critical for cancer cell survival in dogs and offers an opportunity for therapeutic intervention. BMC Vet Res 2012, 8:73.

32. Sakr RA, Weigelt B, Chandarlapaty S, Andrade VP, Guerini-Rocco E, Giri D, $\mathrm{Ng}$ CK, Cowell CF, Rosen N, Reis-Filho JS: PI3K pathway activation in high-grade ductal carcinoma in situ-implications for progression to invasive breast carcinoma. Clin Cancer Res 2014, 20:2326-2337.

33. Rexer BN, Chanthaphaychith S, Dahlman KB, Arteaga CL: Direct inhibition of $\mathrm{PI} 3 \mathrm{~K}$ in combination with dual HER2 inhibitors is required for optimal antitumor activity in HER2+ breast cancer cells. Breast Cancer Res 2014, 16:R9.

34. Toker A, Yoeli-Lerner M: Akt signaling and cancer: surviving but not moving on. Cancer Res 2006, 66:3963-3966. 
35. Schlieman MG, Fahy BN, Ramsamooj R, Beckett L, Bold RJ: Incidence, mechanism and prognostic value of activated AKT in pancreas cancer. Br J Cancer 2003, 89:2110-2115.

36. Altomare DA, Wang HQ, Skele KL, De Rienzo A, Klein-Szanto AJ, Godwin AK, Testa JR: AKT and mTOR phosphorylation is frequently detected in ovarian cancer and can be targeted to disrupt ovarian tumor cell growth. Oncogene 2004, 23:5853-5857.

37. Lin HJ, Hsieh FC, Song H, Lin J: Elevated phosphorylation and activation of PDK-1/AKT pathway in human breast cancer. Br J Cancer 2005, 93:1372-1381.

38. Sarker D, Reid AH, Yap TA, De Bono JS: Targeting the PI3K/AKT pathway for the treatment of prostate cancer. Clin Cancer Res 2009, 15:4799-4805.

39. Kumar A, Rajendran V, Sethumadhavan R, Purohit R: AKT kinase pathway: a leading target in cancer research. Cancer Cell 2003, 4:257-262.

40. Song G, Ouyang G, Bao S: The activation of Akt/PKB signaling pathway and cell survival. J Cell Mol Med 2005, 9:59-71.

41. Yap TA, Garrett MD, Walton MI, Raynaud F, De Bono JS, Workman P. Targeting the PI3K-AKT-mTOR pathway: progress, pitfalls, and promises. Curr Opin Pharmacol 2008, 8:393-412.

42. Onishi K, Higuchi M, Asakura T, Masuyama N, Gotoh Y: The PI3K-Akt pathway promotes microtubule stabilization in migrating fibroblasts. Genes Cells 2007, 12:535-546.

43. Yadav V, Denning MF: Fyn is induced by Ras/PI3K/Akt signaling and is required for enhanced invasion/migration. Mol Carcinog 2011, 50:346-352.

44. Folgiero V, Bachelder RE, Bon G, Sacchi A, Falcioni R, Mercurio AM: The alpha6beta4 integrin can regulate ErbB-3 expression: implications for alpha6beta4 signaling and function. Cancer Res 2007, 67:1645-1652.

45. Park BK, Zeng X, Glazer Rl: Akt1 induces extracellular matrix invasion and matrix metalloproteinase-2 activity in mouse mammary epithelial cells. Cancer Res 2001, 61:7647-7653.

46. Enomoto A, Murakami H, Asai N, Morone N, Watanabe T, Kawai K, Murakumo Y, Usukura J, Kaibuchi K, Takahashi M: Akt/PKB regulates actin organization and cell motility via Girdin/APE. Dev Cell 2009, 9:389-402.

47. Kim D, Kim S, Koh H, Yoon SO, Chung AS, Cho KS, Chung J: Akt/PKB promotes cancer cell invasion via increased motility and metalloproteinase production. FASEB J 2001, 15:1953-1962.

48. Tanno S, Mitsuuchi Y, Altomare DA, Xiao GH, Testa JR: AKT activation up-regulates insulin-like growth factor receptor expression and promotes invasiveness of human pancreatic cancer cells. Cancer Res 2001, 61:589-593.

49. Grille SJ, Bellacosa A, Upson J, Klein-Szanto AJ, Van Roy F, Lee-Kwon W, Donowitz M, Tsichlis PN, Larue L: The protein kinase Akt induces epithelial mesenchymal transition and promotes enhanced motility and invasiveness of squamous cell carcinoma lines. Cancer Res 2003, 63:2172-2178.

50. Vivanco I, Sawyers CL: The phosphatidylinositol 3-Kinase AKT pathway in human cancer. Nat Rev Cancer 2002, 2:489-501.

51. Luo C, Wu Q, Huang XN, Sun AS, Shi JS: Ginkgo biloba leaf extract enhances levels of caspase-3 and amyloid precursor protein in normal rat hippocampus. Acta Pharmacol Sin 2003, 24:152-156.

52. Hayflick L, Stinebring WR: Intracellular growth of pleura pneumonia like organisms (PPLO) in tissue culture and in ovo. Ann N Y Acad Sci 1960, 79:433-449.

53. Taylor G, Taylor-Robinson D, Slavin G: Effect of immunosuppression on arthritis in mice induced by Mycoplasma pulmonis. Ann Rheum Dis 1974, 33:376.

54. Caron J, Ouardani M, Dea S: Diagnosis and differentiation of Mycoplasma hyopneumoniae and Mycoplasma hyorhinis infections in pigs by PCR amplification of the p36 and p46 genes. J Clin Microbiol 2000, 38:1390-1396.

doi:10.1186/s12935-014-0135-3

Cite this article as: Duan et al:: Activation of EGFR-PI3K-AKT signaling is required for Mycoplasma hyorhinis-promoted gastric cancer cell migration. Cancer Cell International 2014 14:135.

\section{Submit your next manuscript to BioMed Central and take full advantage of:}

- Convenient online submission

- Thorough peer review

- No space constraints or color figure charges

- Immediate publication on acceptance

- Inclusion in PubMed, CAS, Scopus and Google Scholar

- Research which is freely available for redistribution

Submit your manuscript at www.biomedcentral.com/submit
C Biomed Central 